\title{
Severe Dumping Symptoms Are Uncommon Following Transthoracic Esophagectomy But Significantly Decrease Health-Related Quality of Life in Long-Term, Disease-Free Survivors
}

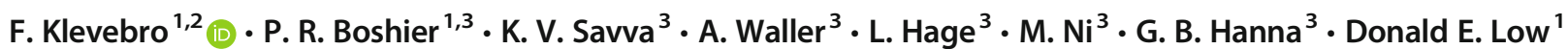

Received: 1 December 2019 / Accepted: 25 May 2020 / Published online: 4 November 2020

(C) 2020 The Author(s)

\begin{abstract}
Background High-quality documentation of dumping symptoms after esophagectomy is currently limited. The aim of the study was to describe the incidence of symptoms associated with dumping syndrome and their relationship with health-related quality of life after esophagectomy.

Methods The study cohort was identified from prospective IRB-approved databases from two high-volume esophagectomy centers. Patients that were alive and without evidence of recurrence in April 2018 completed the validated Dumping Symptom Rating Scale and health-related quality of life questionnaires. Compound dumping symptom score was created by combining the individual scores for severity and frequency for each symptom.

Results In total, 171 patients who underwent esophagectomy 1995-2017 responded to the questionnaires, corresponding to a response rate of $77.0 \%$. Median age was 66 years and median time from operation to survey was 5.5 years. Absent or mild problems in all nine dumping symptoms were reported by 94 (59.5\%) patients; 19 (12.0\%) patients reported moderate or severe problems in at least three symptoms, the most common being postprandial "need to lie down," "diarrhea," and "stomach cramps." Increasing compound dumping symptom score was associated with significantly decreased function scores in all aspects of health-related quality of life except physical functioning $(P<0.005)$.

Conclusions Esophagectomy has the potential to change long-term eating patterns; however, the majority of patients in the study did not have severe postoperative dumping symptoms. On the other hand, moderate-to-severe dumping symptoms, which were reported by $12 \%$ of patients in this study, were strongly associated with decreased health-related quality of life.
\end{abstract}

Keywords Dumping symptoms $\cdot$ Esophagectomy $\cdot$ Health-related quality of life $\cdot$ Long-term follow-up

The study was accepted for the Congress 2020 for the European Society for the Diseases of the Esophagus.

F. Klevebro

fredrik.klevebro@ki.se

Donald E. Low

donald.low@virginiamason.org

1 Department of Thoracic Surgery, Virginia Mason Medical Center, 1100 Ninth Ave, Seattle, WA 98101, USA

2 Karolinska Institutet, Stockholm, Sweden

3 Department of Surgery and Cancer, Imperial College London, London, UK

\section{Introduction}

Esophagectomy is often associated with significant postoperative gastrointestinal symptoms that adversely impact patients' health-related quality of life (HRQOL). ${ }^{1,2}$ Recent improvement in survival of patients undergoing esophagectomy for cancer has increased the focus towards understanding and improving the long-term functional outcomes in this patient population.

The diagnosis of dumping syndrome can be defined as either "early" with symptoms occurring 10-30 min after a meal, or "late" with symptoms presenting $2-3 \mathrm{~h}$ after oral intake. Early dumping symptoms include abdominal pain, diarrhea, borborygmi, nausea, and bloating, as well as vasomotor symptoms including fatigue, a desire to lie down after meals, facial flushing, palpitations, perspiration tachycardia, hypotension, and syncope. Dumping syndrome diagnosis can 
be made with the use of symptom scoring systems or by an oral glucose challenge. ${ }^{3}$ The test is positive for dumping syndrome if the heartbeat increases by $\geq 10$ beats per minute after intake of $50 \mathrm{~g}$ of glucose following a 10-h fast. Blood glucose and hematocrit are also measured, with a hematocrit increase of $\geq 3 \%$ in the first 30 min suggesting early dumping syndrome, and hypoglycemia $2-3 \mathrm{~h}$ after intake suggesting late dumping syndrome. ${ }^{3}$

Symptoms associated with dumping occur in $25-50 \%$ of patients who undergo gastric bypass with Roux-en-Y gastrojejunostomy reconstruction. In approximately $10 \%$ of patients, the condition is severe and persistent enough to warrant the diagnosis of dumping syndrome. ${ }^{3}$ The majority of patients who undergo esophagectomy will have postoperative gastrointestinal symptoms including early satiety and reflux. This is probably caused by exocrine pancreatic insufficiency and delayed gastric conduit emptying, as well as dumping. ${ }^{1,4,5}$ Studies assessing the incidence of dumping syndrome after esophagectomy are insufficient and use different classifications for the syndrome. The overall incidence of dumping symptoms after esophagectomy, according to a recent systematic review article, is approximately $20.2 \%$, and even higher in patients with intraoperative pyloroplasty. ${ }^{4}$

This multi-center study aims to determine the incidence of early dumping symptoms and their effect on health-related quality of life in long-term disease-free survivors after esophagectomy.

\section{Methods}

\section{Patients}

Patients from two tertiary centers for surgical management of esophageal cancer were included in an observational and cross-sectional cohort study. The study cohort was identified from prospective institutionally approved databases, including treatment details of esophageal cancer patients. Eligible patients underwent esophagectomy with intrathoracic gastric tube reconstruction at Virginia Mason Medical Center, Seattle, USA (August 1995 to April 2017) or St. Mary's Hospital, London, UK (February 2005 to May 2017). Inclusion criteria were age $>18$ years, timeframe from surgery $>3$ months, and disease-free status at the time of assessment. Patients were excluded if hospital records or institutional or national cancer registries showed disease recurrence or death. Patients with cognitive dysfunction, including dementia, were also excluded. Patients were recruited to participate in this study either at the time of routine outpatient clinical review or via telephone. This study was approved by the institutional review board, and patients were required to provide informed
Table 1 Patient characteristics

\begin{tabular}{|c|c|}
\hline$N(\%)$ & $N=171$ \\
\hline Age (range) & $66.2(30.0-90.0)$ \\
\hline Time since surgery in years (range) & $5.6(0.3-23.1)$ \\
\hline \multicolumn{2}{|l|}{ Gender } \\
\hline Female & $33(19.3)$ \\
\hline Male & $138(80.7)$ \\
\hline \multicolumn{2}{|l|}{ ASA } \\
\hline I & $2(1.2)$ \\
\hline II & $78(48.5)$ \\
\hline III & $81(50.3)$ \\
\hline Unknown & 10 \\
\hline \multicolumn{2}{|l|}{ Histological tumor type } \\
\hline Adenocarcinoma & $138(80.7)$ \\
\hline Squamous cell carcinoma & $21(12.3)$ \\
\hline Other & $7(4.1)$ \\
\hline Benign & $5(2.9)$ \\
\hline \multicolumn{2}{|l|}{ Tumor location } \\
\hline Proximal-middle esophagus & $14(8.3)$ \\
\hline Distal esophagus & $114(67.9)$ \\
\hline Gastroesophageal junction & $35(20.8)$ \\
\hline Unknown & 3 \\
\hline Benign & $5(3.0)$ \\
\hline \multicolumn{2}{|l|}{ Neoadjuvant treatment } \\
\hline None & $62(36.3)$ \\
\hline Neoadjuvant chemotherapy & 37 (21.6) \\
\hline Neoadjuvant chemoradiotherapy & $72(42.1)$ \\
\hline \multicolumn{2}{|l|}{ Surgical technique } \\
\hline Two-stage esophagectomy (Ivor Lewis) & $85(49.7)$ \\
\hline Left thoracoabdominal esophagectomy & $65(38.0)$ \\
\hline Three-stage esophagectomy (McKeown) & $15(8.8)$ \\
\hline Transhiatal esophagectomy & $4(2.3)$ \\
\hline Total gastrectomy & $2(1.2)$ \\
\hline \multicolumn{2}{|l|}{ Anastomosis location } \\
\hline Thoracic & $94(55.3)$ \\
\hline Cervical & $76(44.7)$ \\
\hline Unknown & 1 \\
\hline \multicolumn{2}{|l|}{ Pylorus } \\
\hline Pyloroplasty & $4(2.3)$ \\
\hline
\end{tabular}

Continuous variables are presented as median and range. Values in parenthesis are percentages. ASA, American Society of Anesthesiology score

consent prior to participation in the manner approved by the local ethical boards reviewing this study.

Clinical data collected from patient records included age, gender, weight, comorbidities, details of neoadjuvant and adjuvant therapy, date of surgery, surgical approach, postoperative complications, clinical and pathological tumor stage, locations, and histology. 
Table 2 Dumping Symptom Rating scores in patients with long-term follow-up after esophagectomy

\begin{tabular}{|c|c|c|c|c|}
\hline $\begin{array}{l}\text { Number of patients responding "yes" }(\%) \\
\text { Reflecting symptoms } 10-30 \text { min after eating }\end{array}$ & $\begin{array}{l}\text { No } \\
\text { problem }\end{array}$ & $\begin{array}{l}\text { Minor/mild } \\
\text { problems }\end{array}$ & $\begin{array}{l}\text { Moderate } \\
\text { problems }\end{array}$ & $\begin{array}{l}\text { Severe/very severe } \\
\text { problems }\end{array}$ \\
\hline Fatigue & $66(41.8)$ & $66(41.8)$ & $18(11.4)$ & $8(5.1)$ \\
\hline Palpitations & $123(79.9)$ & $23(14.9)$ & $5(3.3)$ & $3(2.0)$ \\
\hline Sweating/flushing & $103(66.0)$ & $43(27.6)$ & $7(4.5)$ & $3(1.9)$ \\
\hline Cold sweats & $124(80.5)$ & $24(15.6)$ & $4(2.6)$ & $2(1.3)$ \\
\hline A need to lie down & $93(59.2)$ & $40(25.5)$ & $12(7.6)$ & $12(7.6)$ \\
\hline Diarrhea & $84(53.5)$ & $53(33.8)$ & $11(7.0)$ & $9(5.7)$ \\
\hline Nausea/vomiting & $101(63.9)$ & $43(27.2)$ & $7(4.4)$ & $7(4.4)$ \\
\hline Stomach cramps & $96(61.2)$ & $41(26.1)$ & $12(7.6)$ & $8(5.1)$ \\
\hline Fainting/"shaky" feeling & $100(63.3)$ & $42(26.6)$ & $13(8.2)$ & $3(1.9)$ \\
\hline Pain or vomiting when drinking during a meal & $103(67.3)$ & $35(22.9)$ & $8(5.2)$ & $7(4.6)$ \\
\hline \multicolumn{5}{|l|}{ Heavily sweetened drink in the past week, $N=79$} \\
\hline $\begin{array}{l}\text { Stomach discomfort, fatigue, or fainting when drinking a heavily } \\
\text { sweetened drink }\end{array}$ & $\begin{array}{l}48 / 79 \\
(60.8)\end{array}$ & $21 / 79(26.6)$ & $7 / 79(8.9)$ & $3 / 79(3.8)$ \\
\hline Frequency & Never & Rarely & Weekly & Daily \\
\hline Fatigue & $70(45.6)$ & $24(15.7)$ & $37(24.2)$ & $22(14.4)$ \\
\hline Palpitations & $119(80.4)$ & $10(6.8)$ & $16(10.8)$ & $3(2.0)$ \\
\hline Sweating/flushing & $105(70.5)$ & $18(12.1)$ & $21(14.1)$ & $5(3.4)$ \\
\hline Cold sweats & $125(82.8)$ & $11(7.3)$ & $12(8.0)$ & $3(2.0)$ \\
\hline A need to lie down & $82(54.0)$ & $19(12.5)$ & $34(22.4)$ & $17(11.2)$ \\
\hline Diarrhea & $77(51.0)$ & $21(13.9)$ & $39(25.8)$ & $14(9.3)$ \\
\hline Nausea/vomiting & $96(64.0)$ & $21(14.0)$ & $24(16.0)$ & $9(6.0)$ \\
\hline Stomach cramps & $87(58.0)$ & $20(13.3)$ & $32(21.3)$ & $11(7.3)$ \\
\hline Fainting/“shaky" feeling & $93(61.2)$ & $21(13.8)$ & $31(20.4)$ & $7(4.6)$ \\
\hline \multicolumn{5}{|l|}{ Compound dumping symptom score, median (IQR) 8.0 (2.0-16.0) } \\
\hline & Yes & No & & \\
\hline Avoid certain food & $97(61.4)$ & $61(38.6)$ & & \\
\hline Fatty food & $49(31.0)$ & $109(69.0)$ & & \\
\hline Meat products & $27(17.1)$ & $131(82.9)$ & & \\
\hline High-fiber foods & $18(14.4)$ & $140(88.6)$ & & \\
\hline Fruits & $8(5.1)$ & $150(94.9)$ & & \\
\hline Sugar-rich products & $41(25.9)$ & $117(74.1)$ & & \\
\hline Raw vegetables & $18(14.4)$ & $140(88.6)$ & & \\
\hline Milk or dairy products & $38(24.0)$ & $120(76.0)$ & & \\
\hline Other food & $50(31.6)$ & $108(68.4)$ & & \\
\hline
\end{tabular}

\section{Methodology for Questionnaires}

Each patient that met the inclusion and exclusion criteria and was willing to participate completed a dumping score questionnaire and HRQOL questionnaires: (i) Dumping Symptom Rating Scale adopted from Laurenius et al. ${ }^{6}$, (ii) EORTC QLQ-30, (iii) EuroQol 5D, and (iv) SF-36. The Dumping Symptom Rating Scale assesses the severity and frequency of nine symptoms, occurring 10-30 min after eating, including fatigue, palpitations, sweating/flushing, cold sweats, a need to lie down, diarrhea, nausea/vomiting, stomach cramps, and fainting/"shaky feeling." The scale also includes two questions concerning abdominal problems, faintness, or fatigue when drinking in relation to a meal or when consuming a heavily sweetened drink.

Patients were stratified according to the perceived severity of their symptoms: absent, mild, moderate, and severe. The frequency of symptoms was graded as follows: never, less than weekly, weekly, and daily. Adding the scores for severity and frequency (rated 0-3 for each) created a compound dumping symptom score. Questionnaires were distributed directly to subjects at the time of their routine follow-up clinic appointment or mailed to their home address (with provision for return 
Table 3 Linear regression of HRQOL scores and association with compound dumping symptom score in patients after esophagectomy

\begin{tabular}{|c|c|c|}
\hline \multicolumn{2}{|l|}{ EORTC QLQ-Core30 } & \multirow{2}{*}{$P$ value } \\
\hline Function scores (higher score indicates better & & \\
\hline Global health status & $-0.81(-1.12$ to -0.52$)$ & $<0.001$ \\
\hline Physical functioning & $-0.26(-0.58$ to 0.06$)$ & 0.118 \\
\hline Role functioning & $-0.69(-1.08$ to -0.31$)$ & $<0.001$ \\
\hline Emotional functioning & $-0.89(-1.21$ to -0.56$)$ & $<0.001$ \\
\hline Cognitive functioning & $-0.92(-1.24$ to -0.59$)$ & $<0.001$ \\
\hline Social functioning & $-1.22(-1.61$ to -0.83$)$ & $<0.001$ \\
\hline \multicolumn{3}{|c|}{ Symptom scores (higher score indicates more symptoms) } \\
\hline Fatigue & 1.03 (0.68 to 1.37$)$ & $<0.001$ \\
\hline Nausea and vomiting & $1.24(0.97$ to 1.52$)$ & $<0.001$ \\
\hline Pain & $0.90(0.46$ to 1.34$)$ & $<0.001$ \\
\hline Dyspnea & $0.96(0.57$ to 1.36$)$ & $<0.001$ \\
\hline Insomnia & $0.69(0.22$ to 1.16$)$ & 0.004 \\
\hline Appetite loss & $0.96(0.48$ to 1.45$)$ & $<0.001$ \\
\hline Constipation & $0.61(0.19$ to 1.03$)$ & 0.005 \\
\hline Diarrhea & $1.18(0.77$ to 1.58$)$ & $<0.001$ \\
\hline Financial difficulties & $0.36(-0.06$ to 0.78$)$ & 0.093 \\
\hline \multicolumn{3}{|l|}{ SF-36 (higher score indicates better function) } \\
\hline Physical functioning & $-0.15(-0.58$ to 0.27$)$ & 0.481 \\
\hline Role limitations due to physical health & $-0.83(-1.49$ to -0.16$)$ & 0.016 \\
\hline Role limitations due to emotional problems & $-0.96(-1.54$ to -0.39$)$ & 0.001 \\
\hline Energy/fatigue & $-0.84(-1.19$ to -0.49$)$ & $<0.001$ \\
\hline Emotional well-being & $-0.85(-1.15$ to -0.55$)$ & $<0.001$ \\
\hline Social functioning & $-0.96(-1.31$ to -0.61$)$ & $<0.001$ \\
\hline Pain & $-0.85(-1.30$ to -0.40$)$ & $<0.001$ \\
\hline General health & $-1.04(-1.35$ to -0.73$)$ & $<0.001$ \\
\hline \multicolumn{3}{|c|}{ EuroQol 5D (higher score indicates more problems) } \\
\hline Mobility & $0.01(-0.01$ to 0.02$)$ & 0.305 \\
\hline Self-care & 0.01 ( 0.0 to 0.02$)$ & 0.028 \\
\hline Usual activities & $0.03(0.02$ to 0.04$)$ & $<0.001$ \\
\hline Pain/discomfort & $0.03(0.02$ to 0.05$)$ & $<0.001$ \\
\hline Anxiety/depression & $0.04(0.02$ to 0.05$)$ & $<0.001$ \\
\hline Today's health on a $0-100$ scale & $-0.74(-0.98$ to -0.49$)$ & $<0.001$ \\
\hline
\end{tabular}

\section{Statistical Analysis}

mailing) or sent electronically via a purpose-designed online platform (REDCap). ${ }^{7}$

The EORTC QLQ C30 questionnaire was developed and validated by the European Organisation for Research and Treatment of Cancer (EORTC). The 30-item core questionnaire has nine multi-item scales measuring functions (global quality of life, physical, role, cognitive, emotional and social functioning) and symptoms (fatigue, pain, nausea and vomiting), and six single items measuring general cancer symptoms (dyspnea, appetite loss, insomnia, constipation, diarrhea, and financial impact). ${ }^{8}$ A higher score in the function scales indicates better function. In the symptom scales, a higher score indicates more symptoms. EuroQol 5D and SF-36 are validated and widely used HRQOL questionnaires.
Statistical analyses were performed using StataCorp 2015 (Stata Statistical Software: Release 14. College Station, TX: StataCorp LP). Chi-square and $T$ tests were used for univariate comparisons. Linear regression analyses were performed to calculate mean score differences with $95 \%$ confidence interval (CI) for all HRQOL outcomes. Exploratory factor analysis was performed using SPSS (Ver. 24.0, IBM Corporation, Armonk, USA) to inform the grouping of component scores. Based on the analysis, the average scores for each of the factors identified were assessed. Linear regression was used to assess associations between these factors and the summative quality of life scores. Severity and frequency of each of the 9 symptoms were always in the same dimension. 
Table 4 Quantile regression of clinical and treatment factors and association with compound dumping symptom score in patients after esophagectomy

\begin{tabular}{lll}
\hline & Median change & $P$ value \\
\hline Age & $-0.2(-0.5$ to -0.0$)$ & 0.030 \\
Time from surgery & $0.1(-0.4$ to 0.6$)$ & 0.717 \\
Female vs. male (ref.) & $4.0(-0.7$ to 8.7$)$ & 0.095 \\
American Society for Anesthesiology score* & $-3.0(-6.4$ to 0.4$)$ & 0.081 \\
Malignant vs. benign (ref.) indication & $-16.0(-25.7$ to -6.3$)$ & 0.001 \\
Squamous histology vs. adenocarcinoma (ref.) & $4.0(-1.9$ to 9.9$)$ & 0.185 \\
Neoadjuvant treatment vs. surgery alone (ref.) & $-2.0(-4.1$ to 0.1$)$ & 0.064 \\
Surgical technique** & $0.9(-0.8$ to 2.8$)$ & 0.261 \\
Pyloroplasty vs. no intervention (ref.) & $-2.0(-12.1$ to 8.2$)$ & 0.699 \\
Tumor location (proximal vs. lower or GEJ) & $1.8(-2.5$ to 4.5$)$ & 0.568 \\
Neck vs. chest anastomosis (ref.) & $2.1(-2.18$ to 6.18$)$ & 0.346 \\
\hline
\end{tabular}

*American Society for Anesthesiology Score I, II or III.

**Two-stage esophagectomy (Ivor Lewis), left thoracoabdominal esophagectomy, three-stage esophagectomy (McKeown), transhiatal esophagectomy, or other techniques

\section{Results}

In total, 222 eligible patients were contacted and agreed to participate in the study. Of these, $171(77.0 \%)$ responded to the questionnaires and $159(71.6 \%)$ completed all the included questionnaires. The study cohort underwent esophagectomy 1995-2017; median age was 66 years, and median time from operation to survey was 5.5 years (range 0.3-23.1). All esophagectomies were performed with an open technique; $85(49.7 \%)$ patients had Ivor Lewis esophagectomy, 65 (38.0\%) patients had left thoracoabdominal esophagectomy, of which 54 patients $(83.1 \%)$ received anastomosis in the neck, $15(8.8 \%)$ patients had three-stage esophagectomy (McKeown), 4 (2.3\%) patients underwent transhiatal esophagectomy, and $2(1.2 \%)$ patients were treated with total gastrectomy and lower esophagectomy. Intraoperative pyloroplasty was performed in 4 (2.3\%) patients (Table 1$)$.

Absent or mild problems in all nine dumping symptoms were reported by $94(60.0 \%)$ patients. In total, 19 (12.0\%) patients reported moderate or severe problems in at least three symptoms. The most common severe problems were as follows: "a need to lie down," "diarrhea," and "stomach cramps" in $7.6 \%, 5.7 \%$, and $5.1 \%$ of patients, respectively. Concerning symptomatic frequency, 60 (35.1\%) patients reported at least one weekly or daily symptom rated moderate or severe, the most common being "fatigue" $(N=25,15.8 \%)$, "a need to lie down" $(N=24,15.2 \%)$, and "diarrhea" $(N=19,12.0 \%)$. Due to symptoms of dumping, 97 (61.4\%) patients reported that they avoided certain foods, the most common of which were fatty foods $(N=49,31.0 \%)$, sugar-rich foods $(N=41,25.9 \%)$, and dairy products $(N=38,24.0 \%$; Table 2$)$.

Increased compound dumping symptom score was associated with significantly decreased function scores in all aspects of HRQOL, except physical functioning, when measured with
EORTC QLQ C30 as well as SF36 $(P<0.05)$. There was also a statistically significant association between all measured symptoms on EORTC QLQ C30 and increased compound dumping symptom score. Nausea and vomiting, fatigue, and diarrhea had the strongest correlation to increased dumping symptom score (Table 3 ).

Higher age was associated with a statistically significant decrease in median compound dumping symptom score of 0.24 (95\% confidence interval -0.5 to $-0.0, P=0.030$ ) per year. Malignant indication for esophagectomy was associated with decreased median compound dumping syndrome score compared with benign esophagectomy of - 16.0 (95\% confidence interval -25.7 to $-6.3, P=0.001$ ). Intraoperative pyloroplasty was only used in four patients in the study; there was no significant difference in compound dumping symptom score after pyloroplasty compared with other patients. There was no association with gender, ASA score, neoadjuvant treatment, time from surgery, surgical technique, tumor location, or anastomosis location (Table 4).

Factor analysis determined that the dumping syndrome scale could be classified into five distinct dimensions, which were general symptoms, hemodynamic symptoms, gastrointestinal symptoms, palpitations, and diarrhea. Of these five factors, gastrointestinal symptoms (nausea/vomiting, stomach cramps, and pain or vomiting during meal) had the largest and most reproducible impact on the three summative HRQOL score that were assessed $(P<0.01)$.

\section{Discussion}

This study included a cohort of short- and long-term survivors after esophagectomy from two high-volume centers for esophageal surgery. The results show that the majority of patients do 
not report problems with dumping symptoms after esophagectomy. The study does demonstrate that, in a study population in which pyloric intervention was uncommon, $12 \%$ of the patients report moderate or severe problems with at least three dumping symptoms. This number is lower than previously reported; however, the prevalence of dumping symptoms after esophagectomy has not been studied with clear definitions, which makes comparisons with other studies difficult. ${ }^{4}$ Furthermore, both compound dumping symptom score and the dimension of gastrointestinal symptoms that was identified by factor analysis were strongly associated with decreased HRQOL. The technical evolution of esophagectomy needs to identify factors to limit the incidence of postoperative dumping symptoms to improve long-term gastrointestinal function and HRQOL for patients after esophagectomy.

Strengths of the study include the relatively large study cohort and long-term follow-up, with patients undergoing esophagectomy up to 23 years prior to enrollment, and median time from surgery of 5.6 years. The response rate was high, reducing the risk for selection bias. Patients responded to the validated Dumping Symptom Rating Scale $^{6}$ and widely used and validated HRQOL questionnaires. Study limitations include the lack of one clear definition for dumping syndrome after esophagectomy, and that reported symptoms were not validated with a glucose stress test. ${ }^{3}$ All operations in the study were performed with an open technique, which makes the conclusion primarily applicable to open esophagectomy patients. However, there are no studies indicating that minimally invasive technique is associated with a significant change in conduit function, but this issue needs further attention in future studies. ${ }^{9}$

The prevalence of dumping syndrome after esophagectomy has been described from 0 to $78 \%$ in the literature, with an average of $20.2 \%$ of patients reporting dumping symptoms in a systematic review article. ${ }^{4}$ The heterogeneous definition of dumping syndrome makes epidemiological comparisons difficult. Dumping symptoms were shown to reduce with age in the current study, which has been previously demonstrated. ${ }^{10,11}$ Time from surgery was, however, not associated with decreased symptoms.

The role of pyloroplasty remains controversial in surgery for esophageal cancer. Pyloroplasty has been reported to be associated with an increased risk for dumping syndrome. ${ }^{12}$ In a retrospective study in which $83 \%$ of patients had intraoperative pyloroplasty or pyloromyotomy, $50 \%$ reported postoperative dumping symptoms. ${ }^{11}$ A retrospective study demonstrated a statistically non-significant trend for increased dumping syndrome after pyloromyotomy or pyloroplasty. ${ }^{13}$ The result of a review article from 2001 concluded that, based on scientific evidence, pyloroplasty or pyloromyotomy should not be applied as a standard in esophagectomies with gastric tube reconstruction. ${ }^{14}$ Postesophagectomy care should consider including increased monitoring, and objective testing for postoperative dumping syndrome, and initiating of dietary or medical intervention when testing is positive. Standardized construction of a narrow vertical gastric conduit with an anastomosis either in the neck or high in the chest, rather than pyloric intervention, may decrease the incidence of longterm dumping symptoms and improve HRQOL.

In conclusion, this study shows that early dumping symptoms are associated with significantly decreased HRQOL and, although severe problems are relatively uncommon, the majority of patients in the study reported gastrointestinal symptoms and decreased HRQOL compared with the general population. ${ }^{15}$ Increased focus on patient-reported outcomes of gastrointestinal symptoms and HRQOL is warranted in future prospective studies. Functional outcomes after esophagectomy, especially gastrointestinal symptoms, associated with dumping syndrome can be improved to increase HRQOL and survivorship for patients after esophagectomy.

Acknowledgments Open access funding provided by Karolinska Institute. We thank Bonnie Marston for language editing of the manuscript.

Funding F. Klevebro is the recipient of the 2018-2019 Ryan Hill Research Fellowship.

\section{Compliance with Ethical Standards}

This study was approved by the institutional review board, and patients were required to provide informed consent prior to participation in the manner approved by the local ethical boards reviewing this study.

Conflict of Interest The authors declare that they have no conflict of interest.

Open Access This article is licensed under a Creative Commons Attribution 4.0 International License, which permits use, sharing, adaptation, distribution and reproduction in any medium or format, as long as you give appropriate credit to the original author(s) and the source, provide a link to the Creative Commons licence, and indicate if changes were made. The images or other third party material in this article are included in the article's Creative Commons licence, unless indicated otherwise in a credit line to the material. If material is not included in the article's Creative Commons licence and your intended use is not permitted by statutory regulation or exceeds the permitted use, you will need to obtain permission directly from the copyright holder. To view a copy of this licence, visit http://creativecommons.org/licenses/by/4.0/.

\section{References}

1. Burrows WM. Gastrointestinal function and related problems following esophagectomy. Semin Thorac Cardiovasc Surg 2004; 16: 142-151.

2. Derogar M, Lagergren P. Health-related quality of life among 5year survivors of esophageal cancer surgery: a prospective population-based study. J Clin Oncol 2012; 30: 413-418. 
3. Berg P, McCallum R. Dumping Syndrome: A Review of the Current Concepts of Pathophysiology, Diagnosis, and Treatment. Dig Dis Sci 2016; 61: 11-18.

4. Boshier PR, Huddy JR, Zaninotto G, Hanna GB. Dumping syndrome after esophagectomy: a systematic review of the literature. Dis Esophagus 2017; 30: 1-9.

5. Huddy JR, Macharg FM, Lawn AM, Preston SR. Exocrine pancreatic insufficiency following esophagectomy. Dis Esophagus 2013; 26: 594-597.

6. Laurenius A, Olbers T, Naslund I, Karlsson J. Dumping syndrome following gastric bypass: validation of the dumping symptom rating scale. Obes Surg 2013; 23: 740-755.

7. Harris PA, Taylor R, Thielke R et al. Research electronic data capture (REDCap)-a metadata-driven methodology and workflow process for providing translational research informatics support. $\mathrm{J}$ Biomed Inform 2009; 42: 377-381.

8. Aaronson NK, Ahmedzai S, Bergman B et al. The European Organization for Research and Treatment of Cancer QLQ-C30: a quality-of-life instrument for use in international clinical trials in oncology. J Natl Cancer Inst 1993; 85: 365-376.

9. Kauppila JH, Xie S, Johar A et al. Meta-analysis of health-related quality of life after minimally invasive versus open oesophagectomy for oesophageal cancer. Br J Surg 2017; 104: 1131-1140.
10. Law S, Cheung MC, Fok M et al. Pyloroplasty and pyloromyotomy in gastric replacement of the esophagus after esophagectomy: a randomized controlled trial. J Am Coll Surg 1997; 184: 630-636.

11. McLarty AJ, Deschamps C, Trastek VF et al. Esophageal resection for cancer of the esophagus: long-term function and quality of life. Ann Thorac Surg 1997; 63: 1568-1572.

12. Wang LS, Huang MH, Huang BS, Chien KY. Gastric substitution for resectable carcinoma of the esophagus: an analysis of 368 cases. Ann Thorac Surg 1992; 53: 289-294.

13. Antonoff MB, Puri V, Meyers BF et al. Comparison of pyloric intervention strategies at the time of esophagectomy: is more better? Ann Thorac Surg 2014; 97: 1950-1957; discussion 1657-1958.

14. Lerut T, Coosemans W, De Leyn P, Van Raemdonck D. Gastroplasty: yes or no to gastric drainage procedure. Dis Esophagus 2001; 14: 173-177.

15. Nolte S, Liegl G, Petersen MA et al. General population normative data for the EORTC QLQ-C30 health-related quality of life questionnaire based on 15,386 persons across 13 European countries, Canada and the Unites States. Eur J Cancer 2019; 107: 153-163.

Publisher's Note Springer Nature remains neutral with regard to jurisdictional claims in published maps and institutional affiliations. 